\title{
Calculation of tube concrete elements with strengthened cores by numerical method
}

\author{
Oleksandr Palyvoda ${ }^{1,{ }^{*}}$, Dmytro Yermolenko ${ }^{2}$, Oksana Demchenko ${ }^{2}$, Oleksandr Andriichuk ${ }^{3}$, and Oleksandr \\ Nyzhnyk $^{4}$ \\ ${ }^{1}$ Kryvyi Rih National University, Department of Industrial, Civil and Urban Construction, Kryvyi Rih, 50027, Ukraine \\ ${ }^{2}$ Poltava National Technical Yuriy Kondratyuk University, Department of Highways, Geodesy, Land Management and Rural \\ Buildings, Poltava, 36011, Ukraine \\ ${ }^{3}$ Lutsk National Technical University, Department of Automobile Roads and Airfields, Lutsk, 43018, Ukraine \\ ${ }^{4}$ O.M. Beketov National University of Urban Economy in Kharkiv, Department of Urban Construction, Kharkiv, 61002, \\ Ukraine
}

\begin{abstract}
The paper considers the features of formation of finite element models of tube confined concrete structural elements in the form of centrally compressed rod with strengthened cores. The prerequisites, which underlies the proposed approach to the formation of finite element models of tube confined concrete elements with strengthened cores, are given. Lengthwise the tube confined concrete elements have constant dimensions and a set of cross-sectional components. It is proved that the use of high-strength concrete allows performing calculations in the elastic stage of the work of materials. When modeling the work of rod reinforcement in tube confined concrete elements with strengthened cores, it can be represented as an imaginary cylinder with a cross-sectional area equal to the area of the rod reinforcement. The proposed prerequisites for the numerical simulation of the work of tube confined concrete elements with the strengthened cores of the studied types allowed to construct adequate finite element models. The difference in the value of the load-bearing capacity obtained from the results of physical and numerical experimental studies was 5,94...7,72\%.
\end{abstract}

\section{Introduction}

Sustainable development of modern construction requires the use of compressed elements (columns, posts of various purposes), which would have a large bearing capacity. These requirements are fully met by tube confined concrete made up of steel pipes filled with concrete. Due to its numerous advantages (increased strength of concrete core due to volumetric stress state, lack of formwork during construction, significant savings of labour and energy during construction), tube confined concrete has become widespread in construction both in our country and abroad [1]. One of the disadvantages of tube confined concrete, which somewhat restrains its use, is the significant cost of steel, which increases the cost of construction [2]. However, with the use of strengthened cores, significant savings of steel can be made to create a shell, which will increase the technical and economic characteristics of the structure.

It is known that in compressed tube confined concrete elements the active force is perceived by both the tube shell and the concrete core $[3,4]$. If in some way to increase the bearing capacity of the core, then it is possible to reduce the cost of steel for producing a tube confined concrete element with a predetermined bearing capacity [5]. Therefore, the use of a strengthened core will significantly reduce the cost of steel and save on construction.

The variety of possible combinations of the inner core and shell complicates the search for more rational combinations. Conducting experimental studies requires significant material costs. In such circumstances, it is advisable to use the possibilities of the numerical research.

The task was to develop the methods of estimation of the stress-strain state and the calculation of the loadbearing capacity of the compressed rod tube confined concrete structural elements using software complexes that implement the numerical method of the finite element method algorithm taking into account the volumetric stress state of the strengthened core.

World experience shows that deformation and other mechanical characteristics of tube confined concrete elements depend not only on geometrical parameters, but also on the composition of concrete [6] and the method of strengthening the core [7]. Considering such a number of factors requires the construction of complex mathematical models of the tube confined concrete resistance to the external load [8]. The examples of modeling the work of concrete elements by finite element method are known $[9,10,11]$. The models of tube confined concrete considered in these works do not cover different ways of strengthening the core.

\footnotetext{
*Corresponding author: palyvoda87@ukr.net
} 


\section{Main part}

The reinforcement of the core of the concrete element significantly affects its work under load. The method of calculating the load-bearing capacity of such structures should take into account all these features. Therefore, it became necessary to develop recommendations for the assessment of stress-strain state and load-bearing capacity of tube confined elements with strengthened core.

The use of software systems that implement the finite element method for estimating the stress-strain state of load-bearing building structures allows to obtain more widely the fields of stress and strain distribution than is provided by experimental research methods. Establishing a stress-strain state upon reaching a certain limit state makes it possible to obtain the value of the load-bearing capacity of the load-bearing structure in the form of a tube confined concrete compressed rod.

The calculation is based on the following prerequisites:

- the materials that make up the tube confined concrete element are considered as isotropic elastic-plastic;

- between stresses and strains in the materials of the tube confined concrete element, a linear dependence is reached upon reaching the first limit state in strength;

- throughout the deformation process, the longitudinal axis of the tube confined concrete element remains straight;

- the flat section hypothesis is considered valid;

- the geometric dimensions of the cross-section and the physical properties of the materials along the length of the tube confined concrete element do not change;

- we consider that the tube shell, the concrete core and the reinforcements are deformed jointly;

- static condition remains: the amount of effort on the longitudinal axis is zero;

- the tube shell works in a flat stress state; the concrete core - in the bulk; additional rod reinforcement - in the unconfined compression.

\subsection{Calculation of stress-strain state of compressed elements}

The calculation of the stress-strain state and the structural evaluation by numerical method were performed using the SCAD software complex, which implements the finite element method algorithm. Structurally, the model of the prototypes is selected as a complex body [12]. That is, prototypes are presented in the form of enlarged blocks: cores and outer shell (Series I); cores, outer shell and additional core reinforcement (Series II); annular crosssection cores, outer shell and fill (Series IIIa); annular cross-section cores, inner and outer shells and fill (Series IIIb).

In forming the finite element scheme, spatial elements of two types were used: hexagonal (Fig. 1a); octagonal (Fig. 1b).

The design scheme is designed to completely replicate experimental studies. Thus, the bottom base is fixed from vertical displacements ( $Z$ axis). That is, on the node points of the lower edge of the calculation model ligatures of several types are put. Ligatures are placed at the centre point, which prevents it from moving in the direction of the coordinate axes ( $\mathrm{X}, \mathrm{Y}$ and $\mathrm{Z}$ axes).

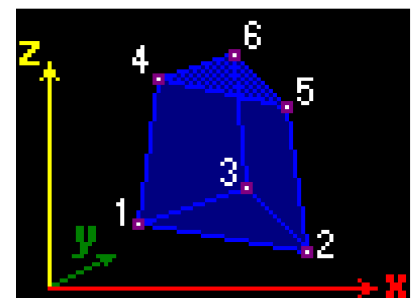

a)

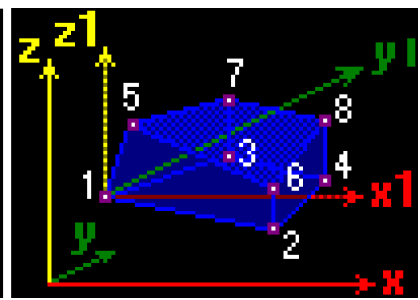

b)
Fig. 1. Types of the finite elements.

The load is transmitted to the upper edge of the prototype. The direction of action of the load corresponds to the direction of the $\mathrm{Z}$ axis. The load is applied through a three-dimensional rigid body.

The rigid body master node is located on the longitudinal axis of the prototypes (Fig. 2).

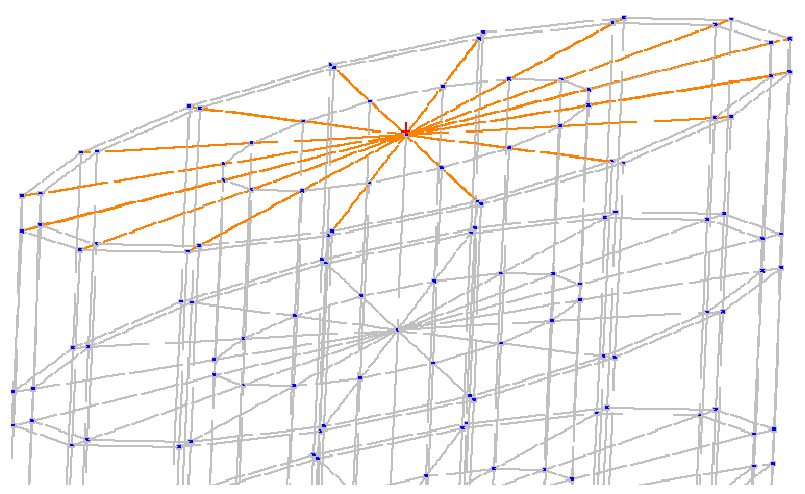

Fig. 2. The rigid body characteristics.

\subsubsection{Calculation of tube confined concrete elements of group I}

Experimental studies of tube confined concrete elements with a core made of high-strength concrete have proved that, by the moment of in the shell, the last of the concrete core works in parallel. Therefore, when developing a methodology for assessing the stress-strain state of such structures, we believe that the tube shell and concrete core work in parallel until the yield of the tube shell begins. Subsequently, the concrete core and shell work together.

The outer shell of the first series samples is an empty cylinder and the cores are a solid cylinder. The outer surface of the core and the inner surface of the shell are common. Therefore, when forming a finite element model, joint node points are introduced on this surface. The shell consists of rectangular spatial finite elements (Fig. 1b) - 16 elements along the perimeter and 16 elements in height (Fig. 3). Two types of spatial elements (Fig. 1) were used to model the core. The load was transmitted to the element through a rigid die (Fig. 2).

The final appearance of the finite element model of tube confined concrete elements with cores of highstrength concrete is shown in Figure 3. 


\subsubsection{Calculation of tube confined concrete elements of group II}

In structural form, the difference between the elements of this type is the presence of core reinforcement in the body of the core. As noted, the rod reinforcement strengthens the resistance of the concrete core in the longitudinal direction, but in the transverse direction it does not work. Therefore, in order to model such an element of the prototype, it is proposed to represent the core reinforcement in the form of an imaginary shell. The final elements that make up this imaginary shell are flat rectangular plates with orthotropic properties. The geometric characteristics of the imaginary shell are characterized by: diameter $\mathrm{D}_{\mathrm{s} 1}$; thickness $\mathrm{t}_{\mathrm{s} 1}$. The rod reinforcement is located around the ring, so the diameter of the imaginary shell is equal to the distance from the vertical axis of the tube confined concrete element to the longitudinal axis of the rod reinforcement. The thickness of the imaginary shell $\mathrm{A}_{\mathrm{s} 1}^{\prime}$ is calculated provided that the area of the core reinforcement $A_{s 1}$ is equal.

\subsubsection{Calculation of tube confined concrete elements of group III}

The prototypes of the third series are the most complex. By design, they are divided into two subgroups. Thus, samples of group IIIa consist of two or three components: a steel outer tube shell; centrifuged concrete cylinder with cavity; concrete solid cylinder. a)

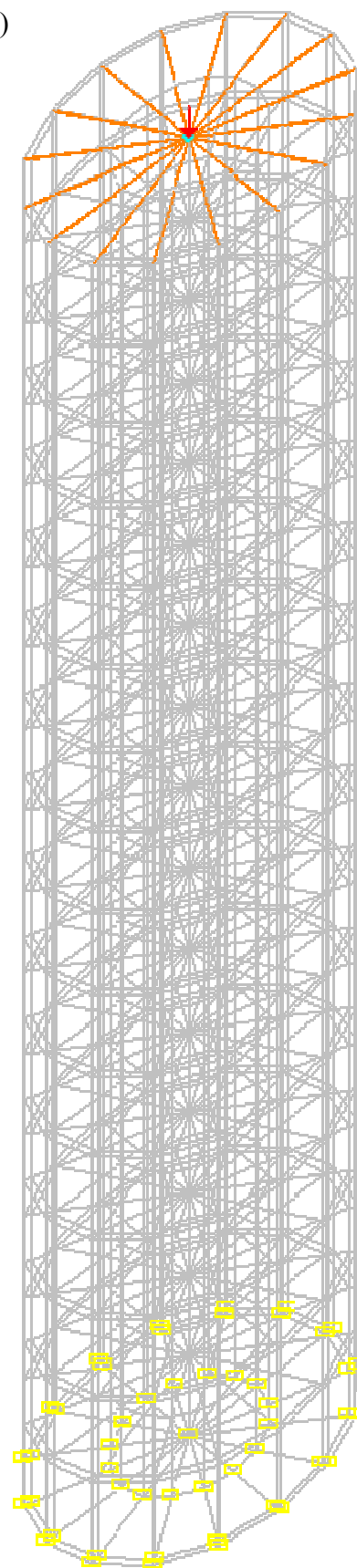

b)

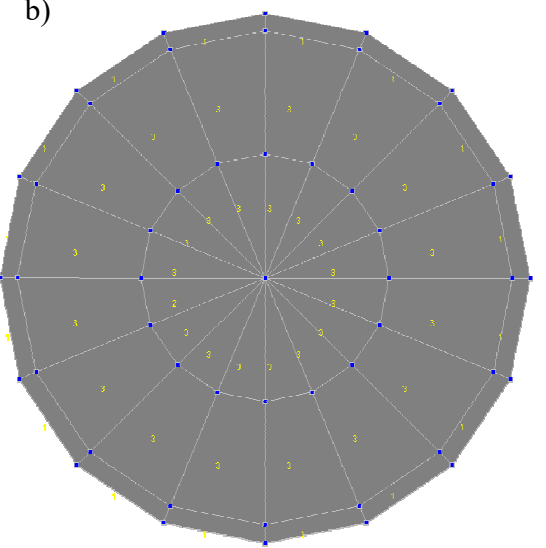

d)

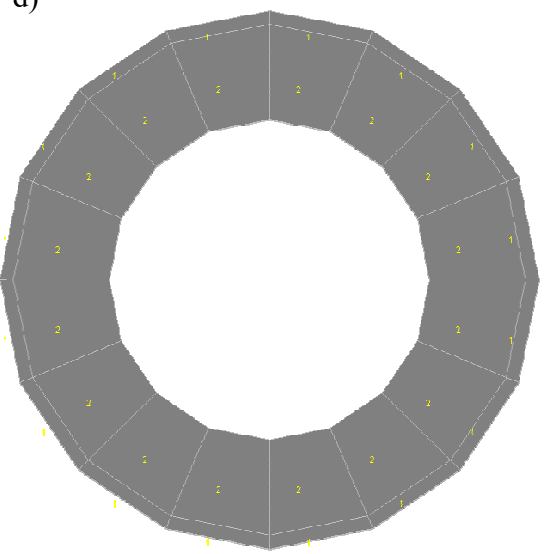

f)

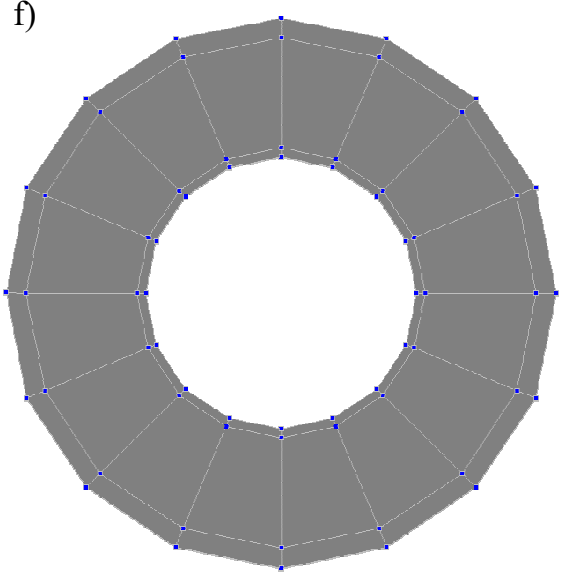

c)

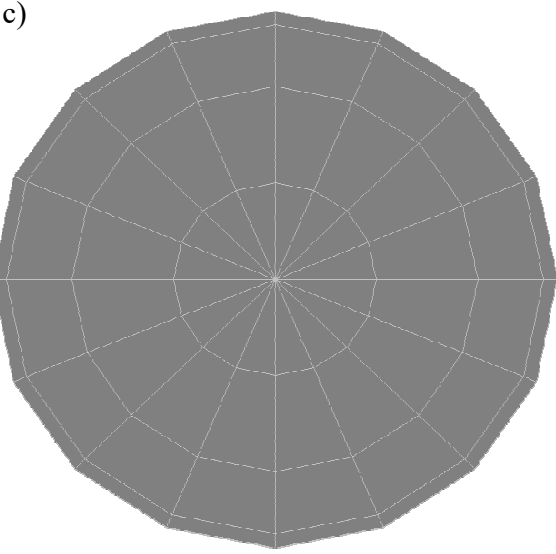

e)

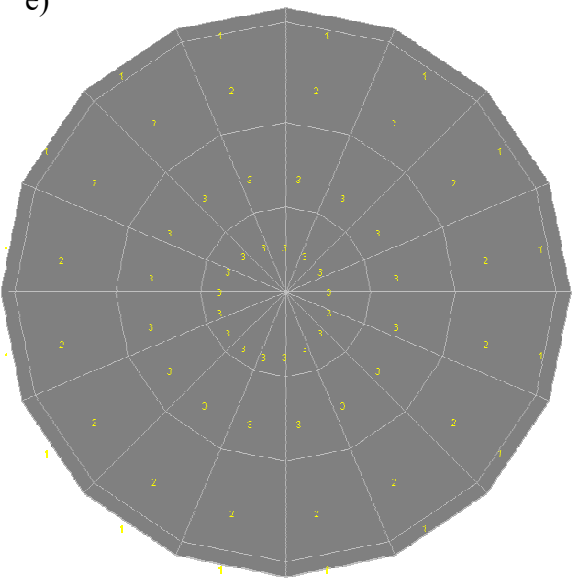

g)

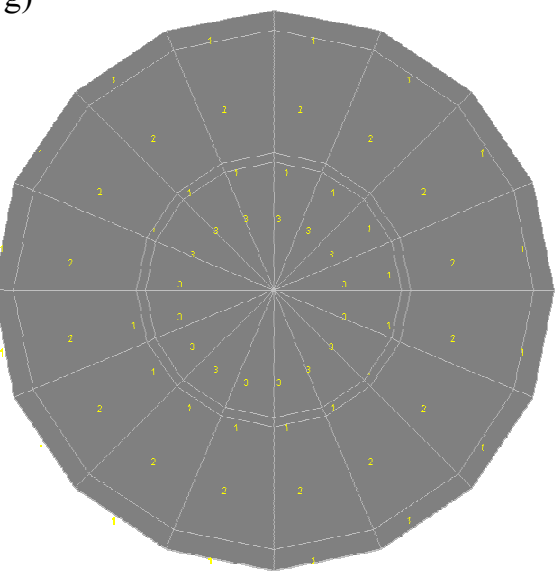

Fig. 3. The general finite element model of the prototypes (a) and cross sections of the prototypes: $b-$ series I; $c-s e r i e s ~ I I ; d-s e r i e s$ TC-IIIa-I-I; e - series TC-IIIb-II-I; f - TC-IIIb-II-I; g - TC-IIIb-II-II. 
The two-component tube confined concrete element of the annular section is modeled with the help of octagonal three-dimensional elements (Fig. 1). The load is applied to the upper edge, but the outer surface of the steel tube shell and the inner surface of the centrifuged concrete cylinder with the cavity remain unloaded. On the common surface at the node points they are connected. The lower edge is covered with ligatures that restrict the movement of the corresponding node points of the finite element model along the $\mathrm{Z}$ axis.

The cross-section of the three-component tube confined concrete elements of the circular cross section of group IIIa includes a fill made of concrete but with other mechanical properties. Therefore, the cross section has finite elements of three types of rigidity. Hexagonal volume finite elements were used to model the filling.

A structural feature of the tube confined concrete elements of the annular section of subgroup IIIb is that the cores are divided into two zones: outer and inner. This division is made by introducing an additional tube shell. The outer and inner tube shells and the concrete layer between them are modeled by octagonal threedimensional elements. The filling of the cavity of the inner tube is modeled by hexagonal volume elements. The load was applied to the upper edge through a rigid die. The center point of the lower edge is covered with ligatures, making it impossible to move along the $\mathrm{X}, \mathrm{Y}$, $\mathrm{Z}$ axes. Other lower edge node points were able to move along the $\mathrm{X}, \mathrm{Y}$ axes.

\subsection{Calculation of the bearing capacity}

The download was done in steps of 0.1 by N1. The corresponding experimental value was accepted as the destructive effort of $\mathrm{N} 1$. Upon reaching $0.8 \cdot \mathrm{N} 1$, the loading rates were assumed to be 0.05 from $\mathrm{N} 1$. According to the results of experimental and numerical studies, the graphs of the development of longitudinal deformations were constructed.

As the bearing capacity of the tube confined concrete elements with strengthened core of all types studied, take the amount of external force that corresponds to the beginning of the steel yield of the outer tube shell. For the purpose of unification in numerical studies, this moment was recorded by the achievement of longitudinal relative deformations of the value $200 \times 10^{-5}$.

The results of the calculation of the bearing capacity of tube confined concrete elements with strengthened cores of all three series are shown in Table 1.

The method of supporting the extreme edges of the prototypes significantly influenced the results of evaluating the bearing capacity by the numerical method. In the SCAD software package, it is possible to provide various fixing methods. So, in the course of numerous experiments, the node points of the upper and lower edges could be fixed from linear and angular movements. For this, ligatures are introduced. The presence of ligatures from angular displacements leads to the appearance of additional force factors that did not appear during the physical experiment. Therefore, these types of ligatures were not used at all. Linear ligatures were set in the direction of the three coordinate axes. Figure 4 illustrates how the number of linear ligatures at each node point affects. So, when the node points of the extreme edges are fixed in the limiting state, the prototype was deformed in the form of a "barrel" (Fig. 4, a). If to establish restrictions on the linear displacements of the node points of the extreme edges along the longitudinal axis $Z$, then in the process of deformation it seems to only increase the thickness (Fig. 4, b). This type of deformation is more consistent with the results of physical experiments.

Table 1. The comparison of the results of experimental and theoretical studies.

\begin{tabular}{|c|c|c|c|c|c|}
\hline \multirow[b]{2}{*}{$\begin{array}{c}\text { Series of } \\
\text { prototypes }\end{array}$} & \multicolumn{3}{|c|}{ Bearing capacity $\left(N_{l}\right), k N$} & \multicolumn{2}{|c|}{$\begin{array}{c}\text { Difference, } \\
\%\end{array}$} \\
\hline & $\begin{array}{l}\text { expe- } \\
\text { rime- } \\
\text { ntal, } \\
N_{I}{ }^{\exp }\end{array}$ & $\begin{array}{c}\text { theoretical } \\
\text { subject to } \\
\text { the elastic } \\
\text { work of } \\
\text { concrete, } \\
N_{I} \text { teorl }\end{array}$ & $\begin{array}{l}\text { theoretical } \\
\text { subject to } \\
\text { the plastic } \\
\text { work of } \\
\text { concrete, } \\
N_{I}^{\text {teor } 2}\end{array}$ & $\begin{array}{c}N_{l}{ }^{\exp } \\
\text { and } \\
N_{l}^{\text {teorl }}\end{array}$ & $\begin{array}{c}N_{I} \exp \\
\text { and } \\
N_{I}^{\text {teor } 2}\end{array}$ \\
\hline TC-I-11 & 652 & 721 & 694 & 10,6 & 6,4 \\
\hline TC-I-12 & 716 & 768 & 739 & 7,2 & 3,2 \\
\hline TC-I-13 & 869 & 922 & 894 & 6,1 & 2,9 \\
\hline TC-I-21 & 1840 & 2066 & 2009 & 12,3 & 9,2 \\
\hline TC-I-22 & 2100 & 2230 & 2207 & 6,2 & 5,1 \\
\hline TC-I-23 & 2400 & 2566 & 2582 & 6,9 & 7,6 \\
\hline TC-I-31 & 2970 & 3273 & 3196 & 10,2 & 7,6 \\
\hline TC-I-32 & 3386 & 3694 & 3572 & 9,1 & 5,5 \\
\hline TC-I-33 & 3636 & 3832 & 3789 & 5,4 & 4,2 \\
\hline TC-II-11 & 1080 & 1176 & 1149 & 8,9 & 6,4 \\
\hline TC-II-12 & 1310 & 1357 & 1359 & 3,6 & 3,7 \\
\hline TC-II-13 & 1490 & 1568 & 1542 & 5,2 & 3,5 \\
\hline TC-IIIa-I-I & 4075 & 4536 & 4450 & 11,3 & 9,2 \\
\hline TC-IIIa-II-I & 4425 & 4753 & 4691 & 6,0 & 7,4 \\
\hline TC-IIIIb-II-I & 1420 & 1536 & 1522 & 8,2 & 7,2 \\
\hline TC-IIIb-II-II & 1800 & 1913 & 1908 & 6,3 & 6,0 \\
\hline
\end{tabular}

In addition, it should be noted that the appearance of such corrugations in the supporting zone significantly increases the stress in the tube shell compared to the middle (in height) section. Such an excess reaches $15-20 \%$. As a consequence, the bearing capacity of the tube confined concrete elements with strengthened cores is reduced in numerous experimental studies. Therefore, the studies used only ligatures along the $\mathrm{Z}$ axis.

Characteristic distribution of stresses on the body of the prototype according to the results of numerical experiments is shown in Figure 5. Figure 6 shows the characteristic distribution of deformations on the tube confined concrete element with strengthened cores.

\subsection{Comparison of calculation results with experimental data}

Numerical modeling allows for a broader analysis of the stress-strain state and bearing capacity of 
compressed bearing structures. In addition, it is possible to carry out an infinite number of studies of structures with different physical and mechanical properties of the materials used and under different types of loading. That which is practically impossible to carry out by physical experiment. But the success of numerical experimental studies is only possible with adequate modeling.

a)
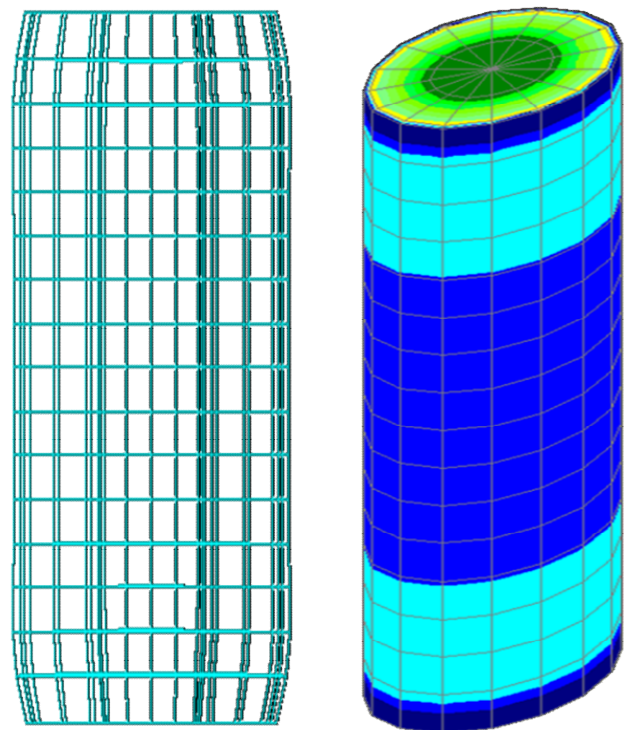

b)
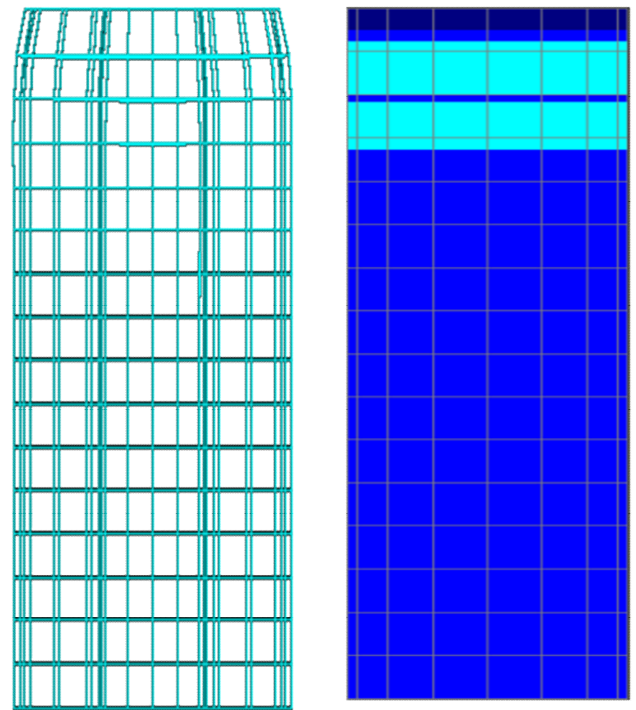

Fig. 4. The analysis of the methods to fix the upper and the lower edges of the prototypes.

In conducting the numerical studies, a number of prerequisites were put forward, which are given in the beginning. Some of these conditions were accepted based on the results of experimental studies and some based on logical considerations. In order to evaluate the degree of importance of these assumptions, the paper compares the values of the bearing capacity obtained from experimental studies with the results of numerical studies on finite element models of the respective prototypes. The theoretical value was calculated by two basic assumptions: the core concrete works as elastic or elastic-plastic material.

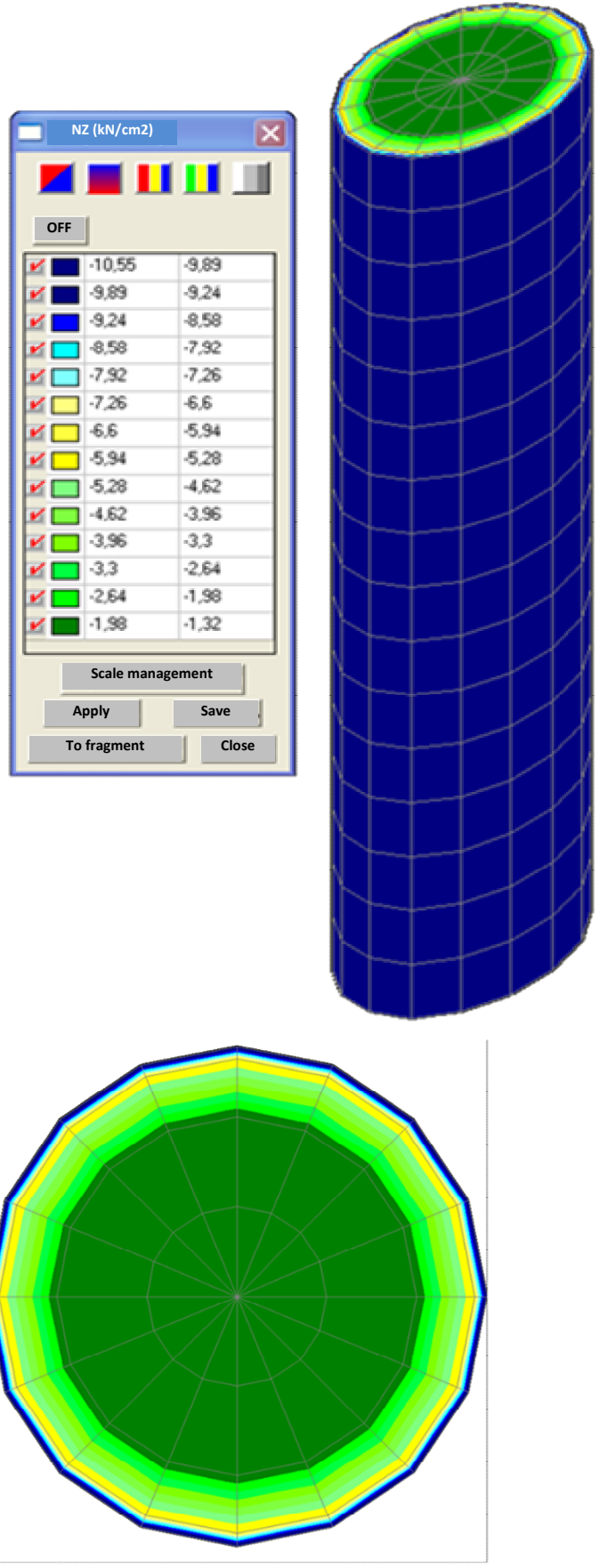

Fig. 5. The distribution of stresses through the tube confined concrete element with strengthened core of series TC-I-22

The results of the comparison of the bearing capacity of the prototypes of groups I, II, III are shown in Table 1.

When the core material works as elastic, the difference between the experimental and numerical results is on average $7.72 \%$. Taking into account the elastic-plastic properties of the core concrete - the average difference was $5.94 \%$.

\section{Conclusions}

Based on the results of numerous studies, the following conclusions can be drawn: 

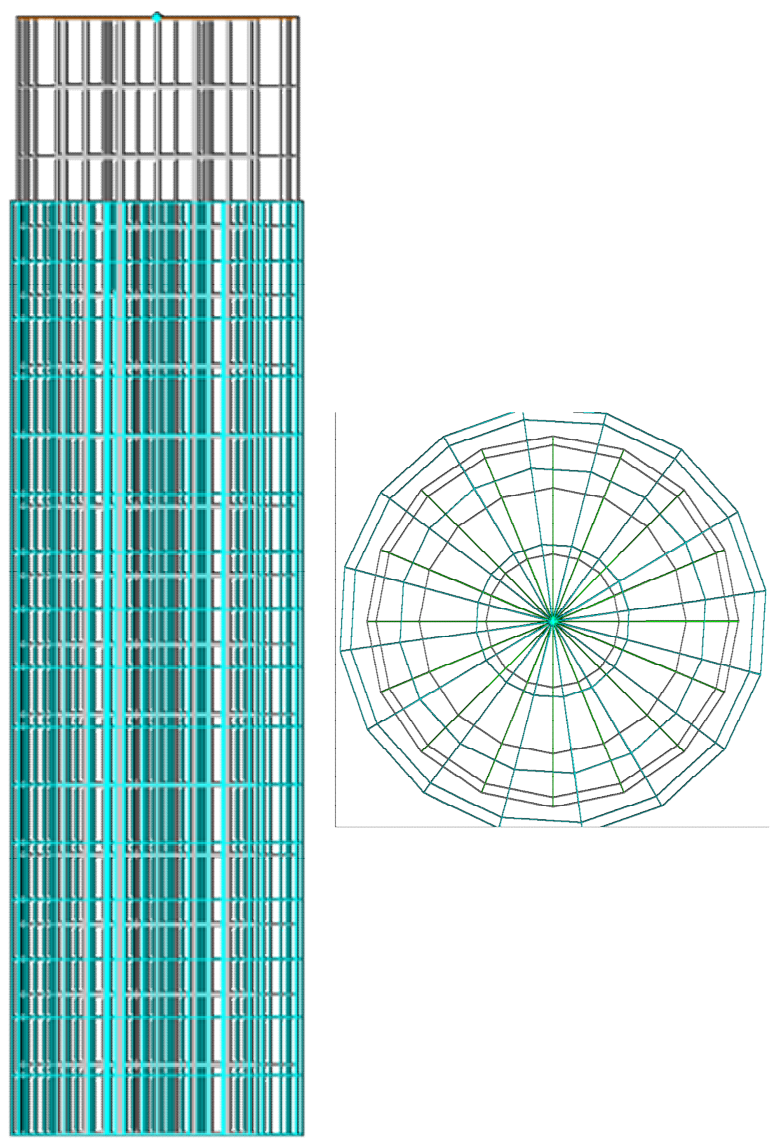

Fig. 6. The distribution of deformations through the tube confined concrete element with strengthened core (group I)

1. With numerous studies of short tube confined concrete elements with strengthened core, it is necessary to provide for the possibility of free movement of the node points of the extreme edges of the finite element model in its plane.

2. When modeling the work of rod reinforcement in tube confined concrete elements wit strengthened core, it can be represented as an imaginary cylinder with a cross-sectional area equal to the area of the core reinforcement. The mechanical properties of such a cylinder should have an orthotropic character.

3 . When using high-strength concrete as the core of tube confined concrete elements in numerical studies, it can be considered that they work elastically at all stages of work under load, up to the time of reaching the limit state.

4. The proposed prerequisites for numerical modeling of the work of tube confined concrete elements with strengthened cores of the studied types allowed to construct adequate finite element models. Thus, by comparing the results of physical and numerical experimental studies, the difference between the corresponding bearing capacity was $5.94 \ldots 7.72 \%$. The coefficient of variation is 0.78 .

\section{References}

1. L.I. Storozhenko (ed.), Stalezalizobeton (Steel reinforced concrete) (PolNTU, Poltava, 2006)
2. L.I. Storozhenko. D.A. Yermolenko, O.I. Lapenko, Trubobeton (Tube confined concrete). (Poltava, 2009)

3. C.S. Huang, Y.-K. Yeh, G.-Y. Lie, H.-T. Hu, K.C. Nsai, Y.T. Weng, S.H. Wang, M.-H Wu., J. Struct. Eng. 9, 1222-1230 (2002)

4. A. Kuranovas, A.K. Kvedaras, J. Civ. Eng. and Manag. 13(2), 131-141 (2007)

5. Z.-W. Yu, F.-X. Ding, C.S. Cai, J. Constr. Steel Res. 63, 165-174 (2007)

6. F.A. Issers, M.G. Bulgakova, N.I. Vershinina, Beton i zhelezobeton 3, 6-9 (1999)

7. A.S. Kuznetsov. Dissertation, Nosov Magnitogorsk State Technical University, 2007

8. V.V. Goriev. V.V. Filippov, N.Y. Tezikov, Matematicheskoie modellirovanie pri raschetah $i$ issledovaniiah stroitelnyh konstruktsyi (Mathematical modeling in the calculations and studies of building structures). (Vysshaia shkola, Moscow, 2002)

9. M.F. Javed, N.H. Ramli, S. Kashif-ur-Rehman, N.B. Khan, Finite element analysis on the structural behaviour of square CFST beams. IOP Conf. Series Mat. Sc. and Eng. 210, 1-12 (2017)

10. T. Goel, A.K. Tiwary, Finite element modeling of circular concrete filled steel tube (CFST), Ind. J. of Sc. and Techn. 11, 34 (2018). doi:10.17485/ijst/2018/v11i34/130853

11. J. Moon, H.-J. Ko, M. H.-E. Lee, in Proceedings of the Thirteenth East Asia-Pacific Conference on Structural Engineering and Construction (EASEC13), Sapporo, 11-13 September 2013

12. O.A. Palyvoda, Dissertation, National Aviation University, 2016 